\title{
Employee Engagement at Leading Manufacturer of Industrial Explosives
}

\author{
${ }^{1}$ Mr. Santosh Dwivedi, ${ }^{2}$ Ms. KanchanTolani, ${ }^{3}$ Mr. ParagGokhale \\ ${ }^{1}$ DGM, Corporate HR \\ ${ }^{2}$ Assistant Professor, Shri Ramdeobaba College of Engineering and Management, Nagpur. \\ ${ }^{3}$ Assistant Manager, Corporate HR \\ Email: Kanchan.tolani24@gmail.com
}

Received: $20^{\text {th }}$ September 2018, Accepted: $11^{\text {th }}$ October 2018, Published: $31^{\text {st }}$ October 2018

\begin{abstract}
In recent times, Employee Engagement at work place has gained significant importance. It is said that employee engagement helps an organization to achieve all the desirable outcomes such as employee productivity, less employee turnover, less absenteeism and high profits (Wagner \& Harter, 2006). Engaged employees tend to show enthusiasm, and high involvement at workplace. In the highly dynamic work environment, employee engagement can act as one element which can help any organization to gain competitive advantage. It has thus become important for organizations to not only identify the level of engagement of employees but also to formulate strategies which can ensure full engagement. Thus the current paper focuses on determining the level of engagement at leading Manufacturer of Industrial Explosives, Nagpur. As the company is planning to make their HR processes robust. The company is also in the process of digitalization of its HR activities. Employee engagement will play a key role in the smooth implementation of these plans. Thus the company has made an attempt to determine the level of engagement of its employees. The data for the study was collected with the help of structured questionnaire. The questionnaire was based on five parameters namely; Communication, Work Environment \& Culture, Learning and Development, 360 degree feedback, Rewards, Recognition and Job Satisfaction. As the company keeps people first, the overall findings indicate that employees in the company are highly engaged.
\end{abstract}

Keywords

Employee Engagement, Productivity, Culture, Values

\section{Introduction}

In recent times, Employee Engagement at work place has gained significant importance. Studies suggest that employee engagement is a factor that contributes directly to organizational success and financial performance. (Bates, 2004). It is said that employee engagement helps an organization to achieve all the desirable outcomes such as employee productivity, less employee turnover, less absenteeism and high profits (Wagner \& Harter, 2006). Employee Engagement contributes to positive business outcomes across all the businesses.

Though there are many definitions of Employee Engagement, it is most frequently defined as emotional and mental commitment to the organization (Richman, 2006). According to Kahn (1990), employee engagement is the active involvement of an employee in behaviors that promote organization success. Engaged employees tend to display characteristics such as dedication, positivity, responsibility and commitment. (Schaufeli et al. 2002). An engaged employee is an individual who is fully involved in his/her work. Engagement at work is also considered a combination of commitment, productivity, loyalty and ownership (Wellins and Concelman, 2005). According to a study by Rothbard, (2001) that there are two important elements of Employee Engagement; Attention and Absorption. Attention refers to the amount of time one spends in thinking about the job \& Absorption refers to the extent to which an individual is immersed in his/her job role.

Employee engagement is not just simple job satisfaction or mere loyalty to the organization. It is more about passion and belongingness of employee towards their organization. It is the zeal to extend maximum efforts for the success of the enterprise. (William Macey et al, 2008). Various observable behaviors associated with employee engagement are organizational citizenship behavior and prosocial behaviors.

There are three categories in which employees can be put on the basis of their engagement levels.

1) Actively engaged

2) Not engaged

3) Disengaged 
For any organization to change the price or quality of products is comparatively easy but to create a workforce which is engaged is highly difficult. It has been argued that in the highly dynamic work environment, employee engagement can act as one element which can help any organization to gain competitive advantage (Jamie Gruman et al, 2011). It has thus become important for organizations to not only identify the level of engagement of employees but also to formulate strategies which can ensure full engagement. (Gerard Seijts, et al, 2006). Thus the current paper focuses on determining the level of engagement at leading Manufacturer of Industrial Explosives, Nagpur.

The company has always placed People First. Understanding, Enabling \& Reinforcing Human Capital has been the philosophy. Considering the Market situation \& future prospects, the group has framed the Growth Plans. As a prerequisite, it is vital to map the current status of HR Processes through Employee Engagement Survey. It will help the company to map the Individual, Departmental \& Organizational related engagement as a whole. Solar group is currently planning to make their HR processes robust, they indent to shift from people dependent to process dependent enterprise. For this purpose they are in the process of digitization of their HR activities. Employee engagement will play a key role in the smooth implementation of these plans. Thus the company has made an attempt to determine the level of engagement of its employees as this will act as an opportunity for the company to capture the employee expectations and will act as a foundation of open communication. The survey will help the company to identify the key areas of concern of employees. It will enable the organization to create a scenario of win-win situation for both individuals and organization.

\section{Material \& Methods}

The employee engagement survey was conducted with the help of a structured questionnaire. The questionnaire was based on five parameters namely:

1) Communication,

2) Work Environment \& Culture,

3) Learning and Development,

4) 360 degree feedback,

5) Reward, Recognition \& Job Satisfaction

These parameters were identified after a vigorous thought process and brainstorming done by the senior professional of the organization. The five parameters were formulated considering the Vision, Mission \& Core Values of the company. Due care was taken to ensure that the dimensions used for measuring the employee engagement represented the philosophy of the company.

Based on these five parameters, 60 statements were formed. While formulating the statements, two things were primarily considered which are relevance and simplicity. It was ensured that the questions are easy to understand for everyone in the organization. At the same time it was made sure that the questions are relevant for all the employees across organization. The identified five parameter along with their respective statements were put to three point scale. The designed questionnaire was revised a number of times to avoid any biases or errors.

The sample size taken was 114 employees working in the company. The sampling technique used is convenience sampling.

For the purpose of data collection, the employees were first briefed about the survey and were made aware about the importance and relevance of the activity. This briefing activity was done to take employees in confidence and to ensure that they give accurate and appropriate responses. After the briefing activity the questionnaires were distributed to the employees in batches. The data collected with help of questionnaire was analyzed using Descriptive statistics.

\section{Result and Discussion}

The data collected was analyzed using descriptive statistics. The responses were clubbed into three categories namely, Favorable responses, Neutral and unfavorable responses. Following is the parameter wise done analysis.

\section{1) Communication}

Communication formulates the focus area of any employee engagement idea. A strong communication from top to bottom really helps the employees feel associated with the organization. The communication is not restricted to information but also extends to the roles and responsibilities played by the employee in the organization, communication within the department and between departments.

The study suggest that overall communication at the company is good. Majority of the employees feel that there is no communication gaps in the organization. All the policies are communicated to the employees appropriately. 


\section{2) Work environment and Culture}

The work environment decides the note for the day. There should be mutual respect amongst all the employees no matter to what hierarchy they belong to. The work environment also includes safety \& hygiene, ergonomics, stress levels at workplace, encouragement from leaders, workplace management and many other factors with respect to work environment and culture. The organization takes care of the work life balance for the employees. Despite demographic diversity, how the organization allots work and treats the employees also comes under this part.

Overall the work environment of the company is good. Majority of the respondents feel that the workplace is clean, safe and hygienic. Also the management practices are consistent with organization values.

\section{3) Learning and Development}

Learning and development is a continuous process which is directly linked to the accomplishment of mission and vision of the organization. Under this parameter, initiatives such as induction, training programmes after training need analysis, development of specific skillsets, opportunities for career growth and development, job enrichment and job enlargement are considered to be of high value. Learning and development is not the responsibility of only the employer. Initiatives for self-learning and self-development should be taken from the side of the employees as well.

The current study reveals that company provides plenty of scope for learning and development. Employees feel that there is sufficient scope for career growth opportunities for employees in the organization. Appropriate training programs are organized for employees from time to time to upgrade their skills and competencies.

\section{4) 360 Degree Feedback}

It is important for an organization to use 360 degree feedback in the best possible way. A good leader has to be a true mentor, coach, guide and an ideal image for the employees. Whether the leadership style used is directing, coaching, supporting or delegating; what is important is a bond between the leader and subordinates. A leader will have followers willingly only when he / she is making the career plan for the subordinates, identifying special developmental assignments, values the opinions of juniors, have an open style of leadership, always ready to welcome suggestions and the one who always makes fair decisions without getting influenced by any biases. The immediate manager should always be approachable.

It was found in the present study that the style of leadership existing in the company promotes growth and development. Majority of employees feel that the managers are approachable and provide support from time to time. Leadership style used is democratic and ensures maximum learning of employees.

\section{5) Rewards, Recognition and Job Satisfaction}

Salary increments, promotion, important and new projects to work on are some of the key elements that a productive employee seeks from the organization. Performance management system needs to be easy to understand, communicated at the beginning of the year, participative and collaborative goal setting between the immediate manager and the employee. Planning, monitoring \& mentoring and stocktaking are the three phases of performance management system which is backed up with motivation and rewards \& recognition. The salary ranges should be ideally at par with industries belonging to the same sector.

Employees feel that the system for evaluating the performance of employees is fair and transparent. There is motivation for them to work hard in the company. The timely and constructive feedback is provided to all the employees for their performance improvement.

\section{Conclusion}

Retention of employees have numerous benefits for the organization. The investment in HR functions such as recruitment, training and others are on an increasing rate these days. It is high time for the organizations to understand the need for development of the employees and give a clear thought about the benefits and facilities given to the employee. It is vital for any organization to take care that the employee by maintaining good communication levels, fair and transparent HR practices and policies, role of a leader and a robust and fair performance management system with rewards and recognition.

The organization has always given priority of the employees be it policy formulation or passing on any benefit to the employees. For all the aspects in the current organization, main focus area has always remained as employees. While interacting with the employees, a sense of belongingness was highly felt through the way they were communicating. In the present study, overall the Engagement level of employees at the company is very high. The company gives high value to its employees and works on the principle of "People First". The study suggest that in the dynamic business environment it is vital to map the Individual, Departmental and organizational related 
engagement as a whole. Employee engagement is the only way for organizations to create a competitive edge in today's business scenario. Thus companies on a regular basis should indulge in formulating strategies to improve the engagement level of its employees.

\section{References}

1. Saks, A.M., 2006. Antecedents and consequences of employee engagement. Journal of managerial psychology, 21(7), pp.600-619.

2. Wagner, R. and Harter, J.K., 2006. 12: The elements of great managing (Vol. 978, No. 1-59992). Simon and Schuster.

3. Richman, A.L., Civian, J.T., Shannon, L.L., Jeffrey Hill, E. and Brennan, R.T., 2008. The relationship of perceived flexibility, supportive work-life policies, and use of formal flexible arrangements and occasional flexibility to employee engagement and expected retention. Community, work and family, 11(2), pp.183-197.

4. Schaufeli, W.B., Salanova, M., González-Romá, V. and Bakker, A.B., 2002. The measurement of engagement and burnout: A two sample confirmatory factor analytic approach. Journal of Happiness studies, 3(1), pp.71-92.

5. Wellins, R. and Concelman, J., 2005. Creating a culture for engagement. Workforce Performance Solutions, 4, pp.1-4.

6. Rothbard, N.P., 2001. Enriching or depleting? The dynamics of engagement in work and family roles. Administrative science quarterly, 46(4), pp.655-684.

7. Macey, W.H. and Schneider, B., 2008. The meaning of employee engagement. Industrial and organizational Psychology, 1(1), pp.3-30.

8. Gruman, J.A. and Saks, A.M., 2011. Performance management and employee engagement. Human Resource Management Review, 21(2), pp.123-136.

9. Seijts, G.H. and Crim, D., 2006. What engages employees the most or, the ten C's of employee engagement. Ivey Business Journal, 70(4), pp.1-5 